\title{
The Role of Federal Renewable Fuel Standards and Market Structure on the Growth of the Cellulosic Biofuel Sector
}

\author{
Abstract: This article examines the effect of the Renewable Fuel Standards and market \\ power on the growth of the cellulosic biofuel sector. We develop a sectoral model to \\ show how changes in the regulations governing cellulosic fuel production affect the \\ equilibrium quantity of cellulosic ethanol. Based on model calibration for Washington \\ State, we find that existing low-cost waivers purchased by obligated parties in lieu of \\ cellulosic fuel production negate the effectiveness of the renewable fuel standard to \\ induce the production and consumption of cellulosic biofuels. However, raising waiver \\ price slightly relative to the status quo significantly increases the equilibrium quantity of \\ cellulosic ethanol. The high cost of cellulosic ethanol production is often cited as the \\ cause of the lack of cellulosic ethanol production, which is used to justify low waiver \\ prices. Our policy message is the converse: the low current waiver price significantly \\ contributes to the cellulosic ethanol market stagnation in the context of the current \\ biofuel policy.
}

JEL Classification: Q48; Q16; Q43

Keywords: Cellulosic biofuel; Renewable Fuel Standards; Waiver; Market structure 


\section{Introduction}

The U.S. Energy Independence and Security Act of 2007 (EISA) aims to expand renewable fuel production by mandating the inclusion of renewable fuel in transportation fuel sold in the U.S. The consumption mandate is enforced by the Environmental Protection Agency (EPA) through the Renewable Fuel Standard (RFS), which requires progressively increasing use of renewable fuels. By 2022, the RFS requires the use of 36 billion gallons of renewable fuel, 16 billion gallons of which must be from cellulosic feedstocks. With national petroleum consumption of approximately 292 billion gallons (EIA, 2016), the 36-billion-gallon requirement represents approximately $12 \%$ of total use. However, development of the cellulosic feedstock sector has been slow. Mandates can be reduced when there is inadequate domestic supply, and the EPA has reduced the mandate for cellulosic biofuel every year since the first year of the biofuel requirement in 2010. In 2012, the original EISA mandate of 500 million gallons was reduced by the EPA to 8.65 million gallons.

In addition to the mandate reduction, the EPA can also provide waiver credits to meet the cellulosic biofuel blending obligation. Waiver credits allow fuel producers and fuel importersthe parties obligated to meet RFS requirements, to effectively buy their way out of their obligation to blend cellulosic biofuel. The price of a waiver credit is set by the EPA (GPO, 2011). For 2012, waiver purchases offset production of all but 20,069 gallons of the (reduced) cellulosic fuel mandate of 8.65 million gallons. Thus, waiver purchases have important repercussions on the growth of the cellulosic feedstock sectors.

The cellulosic refining sector is currently in its infancy, so the type of market structure it will have is unclear. A handful of pilot plants began production in 2012 but most of those currently operational started full scale production in the last quarter of 2015 (EIA, 2013a; EPA, 2015). 
With only a handful of commercial cellulosic refiners, an oligopoly market structure may initially exist. However, as technology develops a small number of commercial-scale refiners may coexist with a much larger number of small-scale producers and approximate a competitive market system.

The objective of this article is to examine the effect of the RFS mandate and the potential market structure of the cellulosic refining sector on the growth of biofuel production from cellulosic feedstock. We develop a static sectoral model to analyze the effect of the RFS on the cellulosic refining sector and the interconnecting sectors such as feedstock sectors and the blended fuel sector. The model is calibrated and used to simulate the effect of the current policy along with changes in market power across various sectors of the economy for Washington State, which is selected due to its relative abundance of cellulosic material (Yoder et al., 2010). Our qualitative results are applicable to other states that face the RFS and have a significant amount of cellulosic material. They are also pertinent to other countries considering a policy similar to the RFS that incorporates the option of waiver purchases. Furthermore, our results are useful because we identify regional effects of the RFS policy and provide policy recommendations on increasing growth of cellulosic ethanol production in regions affected by the federal policy. ${ }^{1}$

This article contributes to the existing literature on standards by providing a new, focused examination of the RFS on biofuel industry development, effects of industry structure on production outcomes, and a targeted examination of the effect of waivers on renewable fuel production. To do so, we build on the literature using general equilibrium models to examine environmental standards in general, and a literature focusing on the biofuel RFS specifically.

\footnotetext{
${ }^{1}$ The RFS has the potential to induce technological innovation; however, we only model exogenous and constant technology. Even though we do not directly analyze the effect of the policy on technological adoption, we can draw some inferences about this effect by analyzing the direct effect of the policy on output change in the cellulosic biofuel sector. If there is little output change, there is little incentive to develop and adopt technological innovations.
} 
The theoretical model we analyze in this article is unique from other tax and ratio mandate analyses as we consider the impact of multiple policy instruments on several competitive and imperfectly competitive intermediate good sectors. Helfand (1991) considers ratio mandates which bear some similarity to the policy instruments we consider, but her analysis is restricted to the simplifying cases of linear supply and demand relationships in a single firm framework. Goulder et al. (2014) utilize a general equilibrium model to examine clean energy standards that require a minimum share of energy consumption from clean sources. They demonstrate that under the right conditions, clean energy ratio standards can be more effective than a cap and trade policy. While informative, Goulder et al. (2014) focus on the electricity industry and a comparison of clean energy standards versus cap and trade policies but they do not consider the specifics of the RFS, nor the impact of waivers as specified in the cellulosic fuel mandate. Bovenberg and Goulder (1996) describes the relationship between optimal environmental taxes and intermediate goods, but their analytic results are limited to derivations of optimal tax rates. Fullerton and Heutel (2007) utilize a general equilibrium model that examines the effectiveness of a performance standard, which, in our context, is analogous to requiring lower carbon emissions per unit of blended fuel. They apply their model to a broad set of sectors in the US economy, focusing on the incidence of regulatory burden across inputs, but they do not provide specificity in relation to the RFS examined here.

Several studies have analyzed the impact of the RFS mandates on the production and consumption of renewable fuel, but most focused on corn-based ethanol and other firstgeneration biofuel feedstocks (e.g., Anderson and Coble, 2010; Gallagher et al., 2003; Gardner, 2007; McPhail and Babcock, 2008a, 2008b; McCullough et al., 2011; Westcott and McPhail, 2013, Chen and Khanna 2012). To date, only two studies, Miao et al. (2012) and Chen and 
Khanna (2012), examined how biofuel mandates affect the growth of the cellulosic biofuel industry. The most important of these for our purposes is Miao et al. (2012), who modeled the impact of Renewable Identification Numbers (RINs) — tradable instruments developed by the EPA to implement EISA - on investments in cellulosic biofuel refineries given that the EPA is able to reduce the mandate from the original EISA level. They concluded that a waivable mandate may induce investment if refinery-level marginal costs are increasing but it has no effect on investment level if marginal costs are constant. Neither Miao et al. (2012) nor Chen and Khanna (2012) consider the impact of waiver credits, which allow obligated parties to buy their way out of their cellulosic obligation. Furthermore, both studies use a partial equilibrium model that does not address the interdependence between the feedstock sectors. Our study fills this gap in the literature by analyzing how implementation of the RFS along with changes in market structure, affect production of cellulosic ethanol. The incentives in the RFS to develop the cellulosic biofuel sector are connected to the blended fuel sector.

Our most important findings relate to the effect of the waiver credit on cellulosic market development. We find that when waiver credits are available for purchase at their current prices, an increase in the standards has no effect on the demand for cellulosic ethanol, which we define as ethanol derived from cellulosic feedstock. This should not be surprising because waiver prices have always been below the cost of producing cellulosic ethanol. However, we find that the equilibrium quantity of cellulosic ethanol increases when the price of waiver credits increases. The increase in equilibrium quantity is accompanied by an increase in the capital to labor ratio in the cellulosic refining sector. As more firms enter and market power decreases, we find an increase in cellulosic ethanol production and the marginal effect of the waiver price decreases. We show that the current low price of the waiver credit is a major reason why the industry is not 
developing despite the mandate and current market conditions. Thus, if the objective is to stimulate production of cellulosic ethanol and boost growth of the cellulosic biofuel sector, raising the price of waiver credits will have more impact than increasing the cellulosic fuel mandate, holding all other variables constant.

We provide additional context regarding cellulosic biofuel in the next section. We develop the static sectoral model in the third section. Next, we describe the functional form, model parameters, calibration technique, and data in the fourth section. We provide the simulation results of the model for changes in the standards, price of waiver credits, and market power in the fifth section. Finally, we conclude the study in the last section.

\section{Cellulosic biofuel policy and industry development}

The consumption mandate is implemented via requirements that a minimum proportion of fuel sold by individual fuel refiners, importers and blenders is renewable fuel (EPA, 2007, 2010). One of the sources of renewable fuel is cellulosic feedstock, which can come from field crop residues, energy crops (e.g., switchgrass, hybrid poplar), woody waste in landfills, and forestry residues from logging, tree thinning, mills, and land clearing. The initial RFS for cellulosic biofuels was 100 million gallons for 2010, 250 million gallons for 2011, 500 million gallons for 2012, and 1 billion gallons for 2013.

However, there was essentially no production of cellulosic biofuel in the U.S. until 2012, when only 20,069 gallons were produced by pilot facilities owned and operated by Blue Sugars and KiOR (EPA, 2013a, 2013b; Schill, 2012). The EPA has listed six potential domestic producers of cellulosic ethanol for 2016. They include Quad County Corn Processors in Iowa, a 2 million gallon per year (MGY) facility that started its production in October 2014 and reported 1 million gallons of corn ethanol produced in April 2015 (Lane 2015); POET-DSM's Project 
LIBERTY in Iowa (24 MGY), Abengoa in Kansas (25 MGY), and Dupont in Iowa (30 MGY) with their first production of cellulosic ethanol projected in the last quarter of 2015; and INEOS Bio (8 MGY) that was projected to produce cellulosic ethanol in the first quarter of 2016 (EPA, 2015). ${ }^{2}$ While there has been progress in producing cellulosic biofuel, the volume of production remains very limited despite the initial RFS mandates.

The EPA reduced the RFS mandate in the previous years. The reduction is due to the small projected domestic supply from commercial-scale cellulosic biofuel plants based on the Energy Information Administration's projections, and production plans and reported progress of producers (EPA, 2013a). The EPA reduced the RFS mandate to 6.6 million gallons for 2011 (EPA, 2010), ${ }^{3}$ to 8.65 million gallons for 2012 (EPA, 2012), and to 6.6 million gallons for 2013 (EPA, 2013a). ${ }^{4}$

To implement the EISA, the EPA created RINs as a mechanism for RFS compliance accounting and it has continued under the reduced RFS mandates. A RIN is a unique 38character number assigned to each gallon of renewable fuel produced in the U.S. or imported. When renewable fuel is blended into motor vehicle fuel, the RIN attached to the renewable fuel can be separated, and then the RIN can be sold or used for current or future compliance. The obligated parties (refiners and importers of gasoline and diesel) must comply with the RFS mandate by accumulating enough RINs that meet their renewable volume obligations (RVOs). Obligated parties can either purchase and blend their required volume of biofuel and report the separated RINs to the EPA, or they can buy RINs in a secondary market (McPhail et al., 2011;

\footnotetext{
${ }^{2}$ As of this writing, the actual production of POET-DSM, Abengoa and Dupont in 2015 have not yet been publicly reported.

${ }^{3}$ The EPA's Final Rule for 2011 was accepted in December, 2010.

${ }^{4}$ The revised standard was challenged and the U.S. Court of Appeals for the District of Columbia Circuit ruled that the EPA's methodology for making cellulosic biofuel projections for 2012 was inconsistent with the statute. As a result of the ruling, the EPA revised their regulations and dropped the 2012 cellulosic RFS to zero (EPA, 2013a; Schnepf and Yacobucci, 2013).
} 
Yacobucci, 2013).

In addition to the reductions in EISA's original mandates, the EPA allows the purchase of waiver credits to substitute for actual production/import/consumption of cellulosic biofuels. One waiver credit is applied to one gallon of an obligated party's cellulosic biofuel RVO. Waiver credits can only be used to meet the obligated party's end-of-year compliance. The waiver credit price is determined by the EPA and it is dependent on the average annual wholesale gas price (GPO, 2011). The price for cellulosic biofuel waiver credits were $\$ 1.13$ per credit in 2011, \$0.78 per credit in 2012, and $\$ 0.42$ per credit in 2013 (EPA, 2010, 2012, 2013a). ${ }^{5}$

\section{Theoretical model}

We model a small open economy but allow for regional differences in several key characteristics such as some input prices and refining capacity. ${ }^{6}$ Our static sectoral model includes two feedstock sectors, a cellulosic refining sector, a blended fuel sector, a composite good producing sector, and a consumer sector. The two feedstock sectors are sources of cellulosic feedstock: the agricultural sector, $a$, and the forestry sector, $f$. Output from both sectors is purchased by the composite good sector to produce a final good or the cellulosic refining sector which processes feedstock into cellulosic ethanol. The blended fuel sector, in turn, purchases the cellulosic ethanol along with crude oil to produce blended fuel. All inputs are variable so we do not focus on a short-run analysis and factor prices are endogenous. ${ }^{7}$ Finally, consumers purchase fuel and a composite consumption good. Fig. 1 summarizes the relationship between sectors in the model and highlights the various interdependencies between the sectors of the model.

\footnotetext{
${ }^{5}$ The EPA refunded the obligated parties that purchased waiver credits in 2012 because the cellulosic RFS was vacated as a result of the court ruling (EPA, 2013a).

${ }^{6}$ We do not explicitly model trade with other states but it is implied through the use of corn ethanol and crude oil.

${ }^{7}$ As pointed out by a reviewer, we note that fixing factor prices would be a viable alternative to allowing them to be endogenously determined. We opt to endogenize input prices to allow changes in factor prices resulting from input demand changes in the blended fuel sector to impact factor demand in biofuel-related sectors as an added mechanism for transmitting the effect of federal biofuel policies.
} 


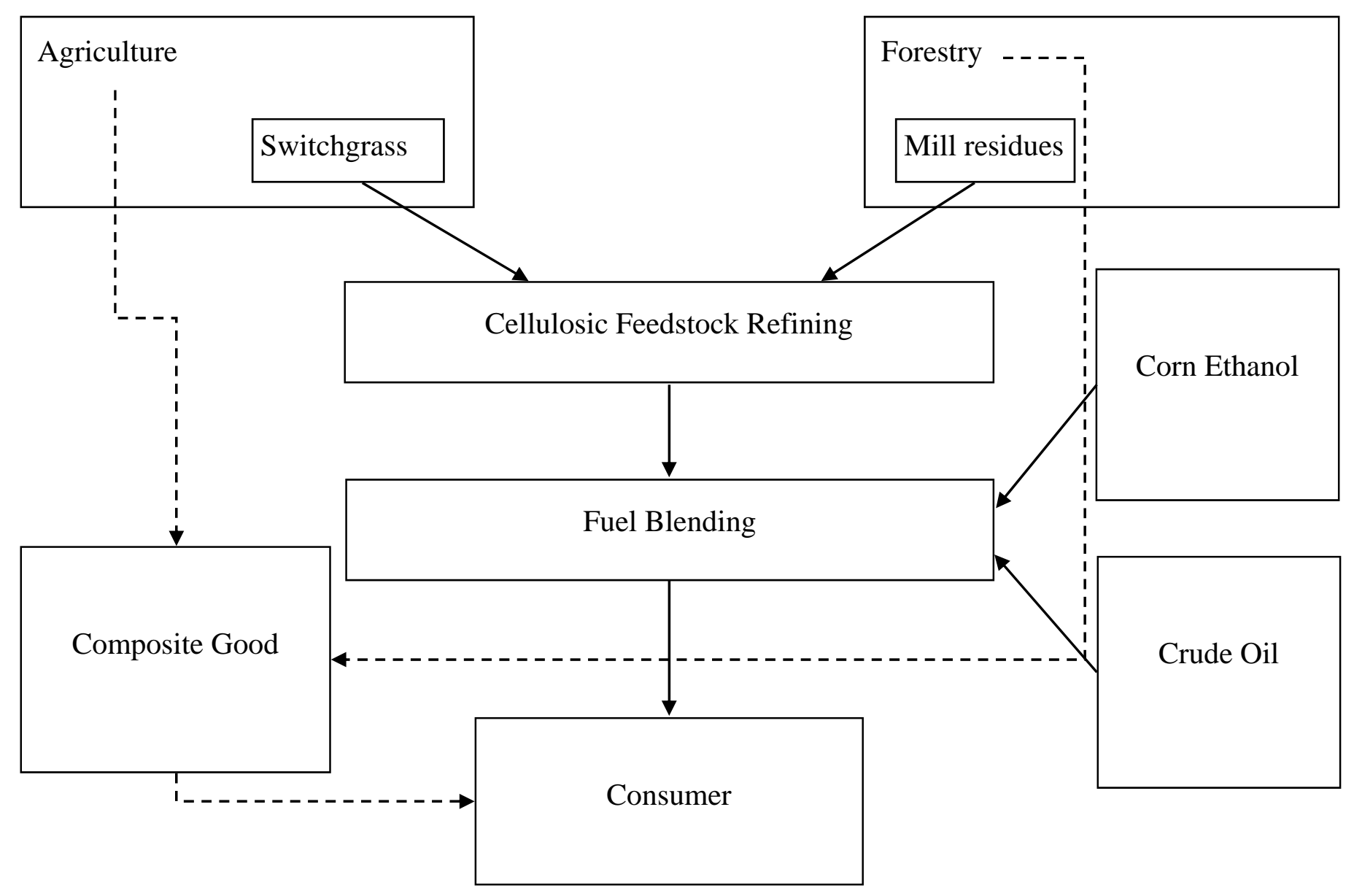

Fig. 1. Sectoral connections in the production and consumption of cellulosic ethanol. (Solid arrows represent the pathway for the production and sale of cellulosic ethanol. Dashed arrows refer to inputs from the agricultural and forestry sectors that are not used to produce cellulosic ethanol and are purchased by the composite good sector to produce a final product that is then sold to the consumer.) 


\subsection{Consumption sector}

Utility, $U(b, x)$, for consumers is increasing and concave in blended fuel consumption, $b$, and a composite good, $x$. Consumers own labor, capital and land resources in the economy so total income in the economy is $I=r \bar{K}+w \bar{L}+m \bar{R}$ where $\bar{K}$ is total capital endowment, $\bar{L}$ is total labor endowment, $\bar{R}$ is total land resource endowment, $r$ is the rental price of capital, $w$ is the wage rate, and $m$ is the rental price of land resource. The following conditions ensure that consumers maximize utility by purchasing blended fuel and a composite good subject to their budget constraint,

$$
\frac{U_{b}(b, x)}{U_{x}(b, x)}=p^{b}
$$

$$
p^{b} b+x=r \bar{K}+w \bar{L}+m \bar{R},
$$

where $p^{b}$ is the output price of blended fuel, the price of the composite good is normalized to one, and subscripts indicate partial derivatives, e.g., $\partial U / \partial b \equiv U_{b}$ or $\partial^{2} U / \partial b \partial x \equiv U_{b x}$. Goods are purchased until the marginal rate of substitution between blended fuel and the composite good is equal to the price ratio in (1) and the budget constraint is satisfied in (2).

\subsection{Feedstock and composite good sectors}

Production in the composite good sector and of feedstock in the agricultural, $a$, and forestry, $f$, sectors utilizes capital, labor and land. Production in each sector is characterized by the production function $Y^{s}=Y^{s}\left(K^{s}, L^{s}, R^{s}\right), \forall s=a, f, x$ which is increasing and concave in all the arguments. Assuming competitive markets, the equilibrium conditions for input use in each sector is such that the value of marginal product of each input is equal to its price, 


$$
p^{s} Y_{K^{s}}^{S}\left(K^{s}, L^{S}, R^{s}\right)-r=0
$$

$$
p^{s} Y_{L^{S}}^{S}\left(K^{s}, L^{S}, R^{s}\right)-w=0,
$$

$$
p^{s} Y_{R^{S}}^{S}\left(K^{s}, L^{s}, R^{s}\right)-m=0
$$

where $p^{s}$ is the output price for $s=a, f, x$.

\subsection{Cellulosic refining sector}

Feedstock output from the agricultural and forest sectors is used along with capital and labor to produce cellulosic ethanol in the cellulosic refining sector. ${ }^{8}$ The production function for the $i^{\text {th }}$ firm in this sector is $Y_{i}^{c}=Y^{c}\left(K_{i}^{c}, L_{i}^{c}, Y_{i}^{a}, Y_{i}^{f}\right)$. Given that there are only a handful of commercial cellulosic refining firms, we assume an oligopoly market structure where there are $n$ identical firms in our region and inputs are simultaneously chosen to solve the Cournot equilibrium. We relax this assumption in our simulations to show how results differ if the market moves from oligopoly to perfect competition. The Cournot best-response functions for each firm are,

$$
\begin{aligned}
& p^{c} Y_{K^{c}}^{c}\left(\frac{1}{n \epsilon^{c}}+1\right)-r=0, \\
& p^{c} Y_{L^{c}}^{c}\left(\frac{1}{n \epsilon^{c}}+1\right)-w=0, \\
& p^{c} Y_{Y^{a}}^{c}\left(\frac{1}{n \epsilon^{c}}+1\right)-p^{a}=0, \\
& p^{c} Y_{Y^{f}}^{c}\left(\frac{1}{n \epsilon^{c}}+1\right)-p^{f}=0,
\end{aligned}
$$

\footnotetext{
${ }^{8}$ Cellulosic feedstock can be refined into several types of fuel, but for the purposes of this article, we assume that
} the cellulosic feedstock is refined into ethanol. 
where $p^{c}\left(\sum_{i=1}^{n} Y^{c}\left(K_{i}^{c}, L_{i}^{c}, Y_{i}^{a}, Y_{i}^{f}\right)\right)$ is the output price of cellulosic ethanol and $\epsilon^{c} \equiv \frac{d n Y^{c}}{d p^{c}} \frac{p^{c}}{n Y^{c}}$ is the price elasticity of demand for cellulosic ethanol. Equations (6) to (9) show that the marginal revenue product from a unit of the input should equal the input price.

\subsection{Blended fuel sector}

We assume that the blended fuel sector takes input and output prices as given, but we relax this assumption later in the simulation. Blended fuel output is based on the production function $Y^{b}\left(Y^{c}, Y^{e}, Y^{o}, K^{b}, L^{b}\right)$ where $Y^{o}$ is crude oil and $Y^{e}$ is corn ethanol. Output is increasing and concave in all arguments. We assume that the blended fuel sector also refines crude oil so that part of capital and labor are used to refine and blend the final fuel.

Each blender is subject to the regulations of the RFS. There are two relevant constraints in our model. The first constrains each blender to use a certain amount of non-advanced biofuels (corn ethanol) as a percentage of crude oil used (McPhail et al., 2011),

$$
Z^{e} Y^{o}=Y^{e}
$$

where $Z^{e}$ is the exogenous percentage requirement for corn ethanol set by the EPA. Since there is a direct relationship between corn ethanol and crude oil use, we can re-write the production function as $Y^{b}\left(Y^{c}, Z^{e} Y^{o}, Y^{o}, K^{b}, L^{b}\right)$ or $Y^{b}\left(Y^{c}, Y^{o}, K^{b}, L^{b} ; Z^{e}\right)$.

Firms are also required to use an amount of cellulosic ethanol equal to the gallons of crude oil purchased multiplied by an exogenous percentage determined annually by the EPA. Unlike the constraint on corn ethanol use, however, firms can purchase waiver credits if they are not able to use cellulosic ethanol. Each blender faces the following blending constraint:

$$
Z^{c} Y^{o}=Y^{c}+\frac{W}{g}
$$

where $Z^{c}$ is the percentage requirement for cellulosic ethanol exogenously set by the EPA, $W$ is 
the value of the waiver credits purchased by the firm and $g$ is the price of waiver credits, so that $W / g$ is the number of waiver credits purchased at the waiver credit price. The waiver credit price is set by the EPA, such that $g=\max \left[0.25, p_{g}-3\right]$ where $p_{g}$ is the average annual wholesale price of gasoline (GPO, 2011). Blender profit is

$$
\begin{gathered}
\pi=p^{b} Y^{b}\left(Y^{c}, Y^{e}, Y^{o}, K^{b}, L^{b} ; Z^{e}\right)-p^{o} Y^{o}-p^{e} Y^{e}-p^{c} Y^{c}-w L^{b} \\
-r K^{b}-W
\end{gathered}
$$

where $p^{b}$ is the blended fuel price, $p^{e}$ is the corn ethanol price and $p^{o}$ is the crude oil price.

Blenders select capital, labor, crude oil, corn ethanol, cellulosic ethanol and the amount of waivers to maximize profit in Equation (12) subject to the RFS mandates in (10) and (11). After substituting the constraints into the objective function, the first-order conditions for profit maximization are,

$$
\begin{aligned}
& p^{b} Y_{Y^{o}}^{b}-p^{o}-p^{e} Z^{e}-g Z^{c}=0, \\
& p^{b} Y_{Y^{c}}^{b}-p^{c}+g=0, \\
& p^{b} Y_{K^{b}}^{b}-r=0, \\
& p^{b} Y_{L^{b}}^{b}-w=0 .
\end{aligned}
$$

Equations (15) and (16) show that the value of the marginal product from capital and labor should be equal to their respective prices. Equation (14) implies that cellulosic ethanol is purchased until the value of the marginal product from the input plus the price of the waiver credit is equal to its price. Here, purchase of the cellulosic ethanol not only increases the value of the marginal product but also reduces the need to buy waiver credits to meet the biofuels mandate. Finally, Equation (13) shows that the purchase of crude oil occurs until the marginal value from crude oil is equal to the price of crude oil plus the marginal cost per unit of crude oil from meeting the two regulatory constraints. The two constraints act as a tax on crude oil use. 


\subsection{Partial equilibrium effects}

We examine the partial equilibrium effect of the RFS and the market structure on demand for cellulosic ethanol in the blended fuel sector. Given the market structure and number of inputs chosen by firms in the blended fuel sector, we need to assume more structure on the production function to sign the comparative statics. Prior literature documents that the elasticities of substitution between the feedstock material needed to make fuel and other inputs are close to zero (Backus and Crucini, 2000). Consequently, we assume that in the production of blended fuel, there is no substitutability between crude oil and labor or between crude oil and capital since crude oil is one of the base inputs needed to make fuel. Given the same reasoning, we also assume no substitutability between cellulosic ethanol and labor or capital. This implies that the cross partial derivatives between inputs in the production function for blended fuel are zero:

$$
Y_{Y^{o} K^{b}}^{b}=0, Y_{Y^{o} L^{b}}^{b}=0, Y_{Y^{c} K^{b}}^{b}=0, Y_{Y^{c} L^{b}}^{b}=0 .
$$

Two parameters capture the effect of the RFS on demand for cellulosic material for firms in the blended fuel sector: $Z^{c}$, the mandated portion of crude oil from cellulosic ethanol and $g$, the price of a waiver credit. First, we consider the effect of the regulatory agency's action in setting $Z^{c}$. Total differentiation of Equations (13) to (16) and imposing (C1) yields

$$
\frac{d Y^{c}}{d Z^{c}}=-\frac{g p^{b^{3}} Y_{Y^{o} Y^{c}}^{b}\left(Y_{L^{b} L^{b}}^{b} Y_{K^{b} K^{b}}^{b}-Y_{K^{b} L^{b}}^{b}\right)}{|H|},
$$

where $|H|$ is the determinant of the Hessian. When a unique profit maximizing solution exists, $|H|>0$ and $Y_{L^{b} L^{b}}^{b} Y_{K^{b} K^{b}}^{b}-Y_{K^{b} L^{b}}^{b}{ }^{2}>0$. From equation (17) a necessary condition for $\frac{d Y^{c}}{d Z^{c}}>0$ is 


$$
Y_{Y^{o} Y^{c}}^{b}<0 .
$$

Thus, when crude oil and cellulosic ethanol are substitutes, an increase in the percentage of required cellulosic ethanol in total fuel produced shifts the demand curve for cellulosic ethanol to the right. Since cellulosic ethanol is added as a regulatory requirement, oil and cellulosic ethanol are substitutes in the production of blended fuel below the blend wall. Thus, condition (C2) is likely satisfied.

We next consider the effect of the regulatory agency's action in setting the price, $g$, of a waiver credit on the demand for cellulosic ethanol. Total differentiation of Equations (13) to (16) with respect to $g$ and imposing (C1) yields,

$$
\frac{d Y^{c}}{d g}=-\frac{p^{b^{3}}\left(Z^{c} Y_{Y^{o} Y^{c}}^{b}+Y_{Y^{o} Y^{0}}^{b}\right)\left(Y_{L^{b} L^{b}}^{b} Y_{K^{b} K^{b}}^{b}-Y_{K^{b} L^{b}}^{b}\right)}{|H|} .
$$

Conditions (C1) and (C2) are sufficient to find a positive relationship between cellulosic ethanol demand and the waiver price. An increase in the price of the waiver acts as a tax on crude oil. As the waiver credit price increases, firms can meet the RFS constraint by increasing demand for cellulosic ethanol and reducing purchases of the relatively more expensive waiver.

We next derive the partial equilibrium effect of a change in market structure within the blended fuel sector on the demand for cellulosic ethanol. Similar to the previous case, we assume that there is no substitutability between the base inputs of agricultural feedstock and forest feedstock with the other inputs, capital and labor, such that

$$
Y_{Y^{a} K^{c}}^{c}=0, Y_{Y^{a} L^{c}}^{c}=0, Y_{Y^{f} K^{c}}^{c}=0, Y_{Y^{f} L^{c}}^{c}=0 .
$$

Totally differentiating (6) to (9) and imposing (C3) yields 


$$
\frac{d Y^{c}}{d n}=\frac{Y^{c} \Theta \Phi\left(Y_{Y^{a}}^{c} Y_{Y^{a} Y^{f}}^{c}+Y_{Y^{f}}^{c} Y_{Y^{a} Y^{a}}^{c}\right)\left(Y_{L^{c} L^{c}}^{c} Y_{K^{c} K^{c}}^{c}-Y_{K^{c} L^{c}}^{c}\right)}{n^{5}\left|H^{c}\right|}
$$

where $\Theta \equiv n p^{c}+Y^{c} p_{Y^{c}}^{c}>0$ is marginal revenue from output in the refined cellulosic sector, $\Phi \equiv\left(n^{2}-1\right) p^{c^{\prime}}+n Y^{c} p_{Y}^{c}{ }^{c} Y^{c}<0$ is the slope of marginal revenue in output, and $\left|H^{c}\right|$ is the determinant of the Hessian. When a unique solution exists, $\left|H^{c}\right|>0$ and $Y_{L^{c} L^{c}}^{c} Y_{K^{c}}^{c} K^{c}-Y_{K^{c} L^{c}}^{c}>$ 0 . Thus, an increase in the number of firms will lead to a rise in the supply of cellulosic ethanol when the following condition holds,

$$
Y_{Y^{a} Y^{f}}^{c} \leq 0
$$

This condition implies that if agricultural and forest feedstocks are substitutes in the production of cellulosic ethanol, a decrease in market power or a change in the market structure from oligopoly to perfect competition leads to an increase in the supply of cellulosic ethanol.

\subsection{Equilibrium conditions}

The effect of the RFS on equilibrium cellulosic ethanol supply may vary as the market structure changes. However, to analyze such an effect, a general equilibrium solution is required. ${ }^{9}$ The equilibrium conditions that solve the model are derived using equations (1)-(9), and (13)-(16) along with market clearing conditions for the inputs,

$$
\begin{aligned}
& \bar{K}=K^{a}+K^{f}+K^{x}+K^{b}+n K^{c}, \\
& \bar{L}=L^{a}+L^{f}+L^{x}+L^{b}+n L^{c},
\end{aligned}
$$

\footnotetext{
${ }^{9}$ Throughout the rest of the paper, we make a distinction between a partial equilibrium effect which only considers the effect within one sector in isolation as opposed to a general equilibrium effect where changes across all sectors in our model are examined.
} 


$$
\bar{R}=R^{a}+R^{f}+R^{x},
$$

as well as the market clearing conditions for the outputs.

In a general equilibrium framework, increased regulatory stringency directly increases demand for cellulosic ethanol as illustrated in our partial equilibrium results, but there is also an increase in supply given a change in the input mix toward the production of feedstocks and ethanol. Thus, one would expect an increase in equilibrium quantity of cellulosic feedstock given a simultaneous rightward shift in its supply and demand. However, the impact on the equilibrium price of cellulosic ethanol is ambiguous and would depend on the relative shifts in the two curves. We turn to simulations and relax conditions (C1) to (C4) to determine the effects of the RFS policy and market structure on the cellulosic refining sector.

\section{Simulation description}

We describe the simulation, including the functional form assumptions, a description of the data, and a discussion of the calibration technique.

\subsection{Functional form}

Constant elasticity of substitution (CES) functional forms are used in three sectors: agricultural, forestry, and composite good production, which is given by:

$$
Y^{s}=A^{s}\left(\sum_{j=\{K, L, R\}} d_{j}^{s}\left(j^{s}\right)^{\rho^{s}}\right)^{1 / \rho^{s}},
$$

for $s=\{a, f, x\}$, where $A^{s}$ is a calibrated scaling/technology parameter, and $d_{K}^{S}, d_{L}^{s}$, and $d_{R}^{S}$ are calibrated share parameters such that $d_{K}^{S}+d_{L}^{S}+d_{R}^{S}=1$. The elasticity of substitution is defined by $\sigma^{s} \equiv 1 /\left(1-\rho^{s}\right)$. CES production functions are chosen over the Cobb-Douglas to provide 
more flexibility in input substitutability between the productive sectors. The CES form also has a sufficient number of parameters for the model calibration based on optimality and market clearing conditions to be exactly identified.

In the feedstock refining and blended fuel sectors, it is unlikely that the elasticity of substitution between capital and labor is similar to that between sources of feedstock or sources of fuel. Consequently, we use nested CES functions in these two sectors to model different elasticities between pairs of inputs. In the feedstock refining sector, we group labor and capital into one pair (with elasticity of substitution equal to $\left.1 /\left(1-\rho_{K^{c} L^{c}}^{c}\right)\right)$ and agricultural and forestry feedstock into the other pair (with elasticity of substitution equal to $1 /\left(1-\rho_{Y^{a}{ }_{Y} f}^{c}\right)$ ). The functional form is given as follows:

$$
\begin{aligned}
Y^{c}=A^{c} & \left(\alpha^{c}\right)\left(\sum_{j=\left\{K^{c}, L^{c}\right\}} d_{j}^{c}(j)^{\rho_{K^{c} L^{c}}^{c}}\right)^{\rho^{c} / \rho_{K^{c} L^{c}}^{c}} \\
& \left.+\left(1-\alpha^{c}\right)\left(\sum_{j=\left\{Y^{a}, Y^{f}\right\}} d_{j}^{c}(j)^{\rho_{Y^{a}}^{c} a_{Y}}\right)^{\left.\rho^{c} / \rho_{Y^{a}}^{c}\right)^{f}}\right)^{1 / \rho^{c}},
\end{aligned}
$$

In the blended fuel sector we also group inputs into two pairs: labor and capital (with elasticity of substitution equal to $1 /\left(1-\rho_{K^{b} L^{b}}^{b}\right)$ ), and crude oil and cellulosic ethanol (with elasticity of substitution equal to $\left.1 /\left(1-\rho_{Y^{c} Y^{o}}^{b}\right)\right)$. 


$$
\begin{aligned}
Y^{c}=A^{b} & \left(\alpha^{b}\right)\left(\sum_{j=\left\{K_{i}^{b}, L_{i}^{b}\right\}} d_{j}^{b}(j)^{\rho_{K}^{b} L^{b}}\right)^{\rho^{b} / \rho_{K^{b} L^{b}}^{b}} \\
& \left.+\left(1-\alpha^{b}\right)\left(\sum_{j=\left\{Y_{i}^{c}, Y_{i}^{o}\right\}} d_{j}^{b}(j)^{\rho_{Y}^{b} c_{Y}^{o}}\right)^{\rho^{b} / \rho_{Y}^{b} C_{Y} o}\right)^{1 / \rho^{b}} .
\end{aligned}
$$

Elasticities of substitution for the blended fuel and feedstock refining sectors are in Table 1.

The utility function is CES, such that $U(b, x)=\left(d_{b} b^{\rho}+d_{x} x^{\rho}\right)^{1 / \rho}$. The share parameters of the utility function and each production function are calibrated and the elasticities of substitution come from the literature. The remaining sector that requires parameterization, the crude oil supply sector, is not modeled explicitly. For simplicity, we assume that crude oil is supplied to fuel blenders at a constant price.

\subsection{Model parameters}

To calibrate and simulate our sectoral model for Washington State, we obtain parameters for the elasticities of substitution, input and output prices, and input and output quantities from the literature to parameterize our model. Table 1 summarizes these parameters. Elasticities of substitution for the production functions are obtained from a variety of different sources. For the agricultural sector, we assume that the main feedstock is switchgrass, and our estimates are from related studies. No information is available for the newly developing cellulosic ethanol refining sector, so we use an elasticity of substitution of 0.5 between labor and capital, treat substitutability between feedstock sources as nearly perfect, and we use an elasticity of substitution of 0.5 between value-added inputs and feedstocks. We apply the same elasticities of 
substitution to the blended fuel sector. The composite good sector represents the production of 
Table 1. Parameter values.

\begin{tabular}{|c|c|c|c|}
\hline Parameters & Value & Units & Source \\
\hline \multicolumn{4}{|l|}{ Elasticity of substitution: } \\
\hline Agricultural sector ${ }^{\mathrm{a}}$ & 0.21 & & Yi et al. (2014) \\
\hline Forestry sector ${ }^{\mathrm{b}}$ & 0.46 & & Daniels (2010) \\
\hline Cellulosic refining sector & & & Assumption \\
\hline Labor/capital & 0.50 & & \\
\hline $\begin{array}{l}\text { Agricultural cellulose/forestry } \\
\text { cellulose }\end{array}$ & $\rightarrow \infty$ & & \\
\hline Value-added/feedstock & 0.50 & & \\
\hline Blended fuel sector & & & Assumption \\
\hline Labor/capital & 0.50 & & \\
\hline Crude oil/cellulosic ethanol & $\rightarrow \infty$ & & \\
\hline Value-added/fuel source & 0.50 & & \\
\hline Composite good sector & 0.50 & & Assumption \\
\hline Consumer's utility function & 0.1068 & & Banks et al. (1997) \\
\hline \multicolumn{4}{|l|}{ Prices: } \\
\hline Wage rate & 36,296 & \$/year & BLS (2013) \\
\hline Rental rate of capital ${ }^{\mathrm{C}}$ & 8,680 & \$/year & ERS (2014) \\
\hline Land resource price & 215 & \$/acre & NASS (2013a) \\
\hline Cellulosic feedstock, agriculture & 65 & $\$ /$ dry ton & U. Kentucky (2013) \\
\hline Cellulosic feedstock, forestry & 52.27 & $\$ /$ dry ton & Gale et al. (2012) \\
\hline Cellulosic ethanol & 2.35 & \$/gallon & GBC (2011) \\
\hline Crude oil & 2.24 & \$/gallon & EIA (2013b) \\
\hline Final blended fuel $^{\mathrm{d}}$ & 3.76 & \$/gallon & EIA (2013c) \\
\hline Corn ethanol price & 2.23 & \$/gallon & EIA (2013a) \\
\hline \multicolumn{4}{|l|}{ Quantities: } \\
\hline Agricultural labor ${ }^{e}$ & 1.16 & Full-time laborers $^{\mathrm{n}}$ & BLS (2013) \\
\hline Agricultural capital $^{\mathrm{f}}$ & 3.79 & Tractors/equipment & NASS (2013b) \\
\hline Agricultural resources & 1,096 & Acres & NASS (2013c) \\
\hline Forestry labor ${ }^{\mathrm{g}}$ & 3.17 & Full-time laborers & BLS (2013) \\
\hline Forestry capital $^{\mathrm{h}}$ & 52.82 & Capital units $^{\circ}$ & Smith (2012) \\
\hline Forestry resources & 17,257 & Acres & Computed \\
\hline Cellulosic refining labor & 22.6 & Full-time laborers & BLS (2013) \\
\hline Cellulosic refining capital & 342.64 & Capital units & WRC (2012) \\
\hline Fuel blending labor ${ }^{\mathrm{i}}$ & 1130 & Full-time laborers & BLS (2013) \\
\hline Fuel blending capital $^{\mathrm{j}}$ & 17,132 & Capital units & WRC (2012) \\
\hline Crude oil & 5.67 & Gallons (bil.) & EIA (2013d) \\
\hline Composite good labor & 15,035 & Full-time laborers & BLS (2013) \\
\hline Composite good capital & 174,157 & Capital units & NASS (2013b), Smith (2012) \\
\hline Composite good resources & 27.65 & Acres (mil.) & NASS (2013c), Smith (2012) \\
\hline Cellulosic feedstock, agriculture ${ }^{\mathrm{k}}$ & 6,575 & Tons & Sims et al. (2010), EIA (2013d) \\
\hline Cellulosic feedstock, forestry ${ }^{k}$ & 5,879 & Tons & Sims et al. (2010), EIA (2013d) \\
\hline Cellulosic ethanol ${ }^{1}$ & 660 & Gallons (th.) & RFSP (2015), EIA (2013d) \\
\hline Blended fuel & 2.60 & Gallons (bil.) & EIA (2013d) \\
\hline Composite good $^{\mathrm{m}}$ & 11.98 & \$ (bil.) & NASS (2013d), Smith (2012) \\
\hline
\end{tabular}

${ }^{a}$ We use estimates from switchgrass production for the agricultural sector.

${ }^{\mathrm{b}}$ The elasticity is an average of three different estimated elasticities between capital and labor, labor and logs, and capital and logs.

${ }^{\mathrm{c}}$ Annual tractor rental rate.

${ }^{\mathrm{d}}$ The final blended fuel price is the 2012 average retail gasoline price for the Western United States less California. ${ }^{\mathrm{e}}$ The input quantity of labor consists of agricultural inspectors, graders and sorters of agricultural products, agricultural equipment operators, and general farmworkers.

${ }^{\mathrm{f}}$ Agricultural capital is computed as an average of the amount of different types of agricultural equipment (tractors) available in Washington State in 2012.

${ }^{\mathrm{g}}$ Labor input in the forestry sector consists of forest and conservation workers, fallers, logging equipment operators, 
and $\log$ graders and scalers.

${ }^{\mathrm{h}}$ Annual operating cost for sawmills multiplied by the number of sawmills in each state, expressed in capital units. ${ }^{\circ}$ ${ }^{\mathrm{i}}$ Labor for the blended fuel sector includes categories for petroleum pump system operators, refinery operators and gaugers.

${ }^{j}$ Total 2012 non-labor capital expenditures, expressed in capital units. ${ }^{\circ}$

${ }^{k}$ We model half the cellulosic ethanol production as derived from agricultural cellulosic feedstock (switchgrass) and half from forestry cellulosic feedstock (mill residues). These values represent the necessary amount of feedstock required to produce those levels in accordance with the conversion factors in Sims et al. (2010).

${ }^{\mathrm{l}}$ Equal to the 2014 RFS mandated level of cellulosic ethanol multiplied by each state's share of national petroleum consumption.

${ }^{\mathrm{m}}$ The sum of total value from agriculture and forestry sectors by state.

${ }^{\mathrm{n}}$ Full-time laborers are those that are employed 40/hrs/wk. for one year.

${ }^{\circ}$ Capital units are expressed in terms of sector-level input expenditure divided by the capital price, e.g. forestry

capital is expressed in units of annual sawmill operating ex-penditure divided by the capital price.

an index of goods which we also have limited information, so we use 0.5 as an estimate. We

conducted a sensitivity analysis on our guesses for the elasticity of substitution by simulating the

results using elasticities ranging from 0.01 to 0.99 in the cellulosic refining and composite good

sectors. It revealed no significant changes in the magnitude or direction in our results. ${ }^{10}$

The Washington State market wage rate from the Bureau of Labor Statistics (BLS) used in

this study is an average of the wage rates for all employment categories related to agriculture,

logging (forestry), and oil refining. We use the 2011 national rental rate of capital specific to

tractors from the Economic Research Service (ERS) of the U.S. Department of Agriculture

(USDA) (ERS, 2014). Data from the National Agricultural Statistics Service (NASS) (2013a) is

used for the land price, for which we use the state-level rental rate of land as a proxy. The output

price of cellulosic feedstock from the agricultural sector (switchgrass) is obtained from a

University of Kentucky (2013) extension publication. ${ }^{11}$ The price for cellulosic ethanol is an

estimate from the POET biorefinery, as reported in the Governors’ Biofuels Coalition (2011). ${ }^{12}$

\footnotetext{
${ }^{10}$ Results are available from the authors upon request.

${ }^{11}$ Currently no centralized market for switchgrass exists, so this figure only represents an educated guess.

12 The POET facility is one of the few cellulosic biofuel refining plants in existence, and the only one with a publicly listed price at the time of this writing.
} 
Labor data for the different sectors is obtained from the BLS (2013). We do not have data describing how much of the total agricultural and forestry labor is currently involved in the respective production of switchgrass and forest residues, so we set the labor input in each of these sectors to match the labor/land ratio observed nationally. The remaining labor is used in the production of the composite good, which is an index of agricultural products not including switchgrass and forestry products not including residues. No data exist for the labor used in the cellulosic ethanol refining sector. The most similar sector to this one in the model is the blended fuel sector, which also refines raw material (crude oil) into a finished product. Accordingly, we set the cellulosic refining sector's labor input equal to the blended fuel sector labor as a proxy. ${ }^{13}$

Capital data are obtained from NASS and various state-level forest service reports. We do not have specific data for capital usage in the production of switchgrass or forest residues, so we employ the same technique used in setting the baseline labor values by setting capital usage to mimic the capital/land ratio observed in national-level, aggregate production. Remaining agricultural and forestry capital is used in the production of the composite good. Capital usage data are unavailable for both the cellulosic ethanol refining and blended fuel sectors, so those levels are set to match the capital used in the production of forest residues.

The amount of agricultural land used in the production of switchgrass is based on the estimated land requirement to produce the observed level of switchgrass production (Woodward, 2008). Land use for the composite consumption good sector is set to the sum of agricultural land not used in switchgrass production and timberland not used in the production of residues.

Since the RFS is only defined at the national level, one challenge in calibration is to approximate the mandate faced by Washington State to obtain an estimate of the amount of

\footnotetext{
${ }^{13}$ While this number will be too high for this industry in its beginning stages, it is a reasonable approximation for the expected steady-state value.
} 
cellulosic feedstock required from both sectors. Even though the mandate is based on a percentage of cellulosic ethanol in blended fuel, we need to obtain an initial target level of total cellulosic ethanol produced as a basis for calibrating feedstock demand and production technology parameters. We approximate this mandated value as $2 \%$ of national cellulosic ethanol production in 2014, where $2 \%$ is the percentage of national petroleum consumption attributed to Washington State in (EIA, 2013d). ${ }^{14}$ With only 33 million gallons of cellulosic ethanol produced nationally in 2014, we estimate Washington State's share at 660 thousand gallons. Also, we assume that half of this amount was produced by the forestry sector and the other half was produced by the agricultural sector. Sims et al. (2010) estimate that between 110 to 270 liters of cellulosic ethanol can be produced from one ton of agricultural feedstocks and between 125 to 300 liters of cellulosic ethanol can be produced from one ton of forest residues. From their analysis, we extrapolate how much feedstock each sector would have to produce to meet the target of 660 thousand gallons of cellulosic ethanol.

\subsection{Calibration}

The first-order conditions resulting from the profit maximization problems in each of the five production sectors and the utility maximization problem in the consumption sector comprise a system of 19 equations (equations (1)-(9) and (13)-(16)). When combined with the share summing restrictions, we have a system of 27 equations which is solved numerically for the 27 unknown parameters in the model, using the price and quantity data as calibration targets. ${ }^{15} \mathrm{We}$ allow one or more of the calibrated parameters to vary and then we solve the system of 19 first-

\footnotetext{
${ }^{14}$ This approximation serves as a necessary starting point for the simulation. When we change this assumption, cellulosic ethanol production necessarily changes, but the qualitative results and implications presented in the following sections remain intact.

${ }^{15}$ Note that due to the static nature of our theoretical model, when we vary the RFS parameter $Z^{c}$, which varies over time, we are re-solving the static model at each new value of $Z^{c}$ that corresponds to the appropriate policy year.
} 
order conditions and 8 market clearing conditions for the 27 endogenous prices and quantities. ${ }^{16}$ In the simulation, we examine changes to key exogenous variables, including the waiver price, $g$, the RFS percentage requirement for cellulosic biofuel, $Z^{c}$, and the number of firms in the cellulosic refining sector, $n .^{17}$

\section{Simulation results}

We simulate the theoretical model to determine the effects of changes to RFS regulations and changes in market power. Note that in all of the results discussed below, the regional production quantity is equal to regional consumption in equilibrium.

\subsection{Change in the cellulosic biofuel percentage standard and price of waiver credits}

In the first series of simulations, we run an experiment to determine the changes in cellulosic ethanol output that occur following progressive increases in the regulatory constraint, i.e., the percentage standard, over time for cellulosic biofuel. Fig. 2 illustrates the cellulosic biofuel percentage standard proposed by the 2007 Energy Independence and Security Act from 2012 through 2022. Due to supply shortages, the cellulosic biofuel percentage standard was readjusted below the originally proposed standard in every year since its inception, from 2011 to 2015. As illustrated in Fig. 3, we find a minimal increase (less than a thousand gallons over 10 years) in the amount of cellulosic ethanol that would be produced by implementing the standards for cellulosic biofuel proposed by EISA through 2022.

\footnotetext{
${ }^{16}$ One equation is dropped in accordance with Walras' Law.

${ }^{17}$ Calibrated parameters are available from the authors upon request. Given our parameter values, we can determine the values of the cross partial derivatives of the production function to verify the validity of conditions (C1) to (C4) in our calibrated model. We find that (C2) and (C4) are very close to zero with values of 0.000001 and 0.00005 , respectively while the values in conditions (C1) and (C3) are close to zero but positive.
} 


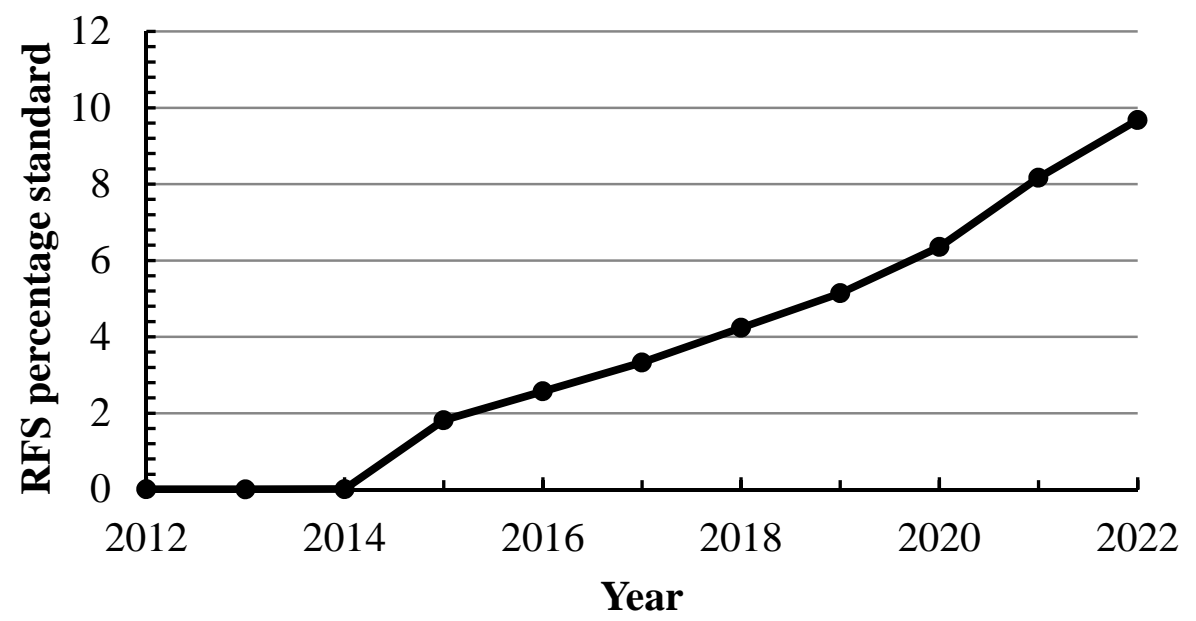

Fig. 2. Revised RFS for percentage of cellulosic ethanol $\left(Z^{c}\right)$ in blended fuel through 2022.

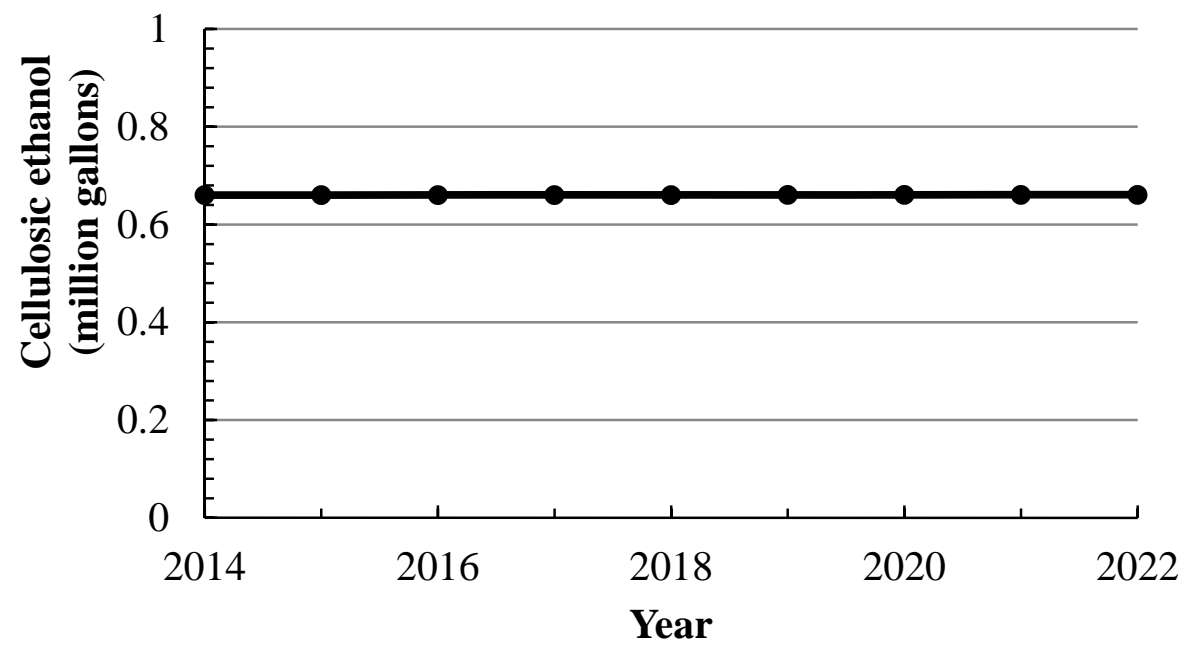

Fig. 3. Simulated effect of the increasing RFS $\left(Z^{c}\right)$ on use of cellulosic ethanol $\left(Y^{c}\right)$.

If the price of cellulosic biofuel waiver credits remains at the 2012 level, blended fuel firms react to the higher standard by simply purchasing more waiver credits as shown in Fig. 4. Because there is no significant increase in the quantity of cellulosic ethanol, the trend in waiver purchases is identical to the increase in the percentage standard. ${ }^{18}$ The general equilibrium result is consistent with the partial equilibrium assessment that a rise in cellulosic biofuel standards

\footnotetext{
${ }^{18}$ Simulations were conducted for all three Pacific Northwest states - Washington, Oregon, and Idaho. Because the results are qualitatively similar for all three states, we report them only for Washington. Simulation results for Oregon and Idaho are available from the authors upon request.
} 
increases the production of cellulosic ethanol. However, our general equilibrium simulations show that the increase is trivial. With the exception of waiver expenditures, all other prices and quantities in the model change by only a trivial amount.

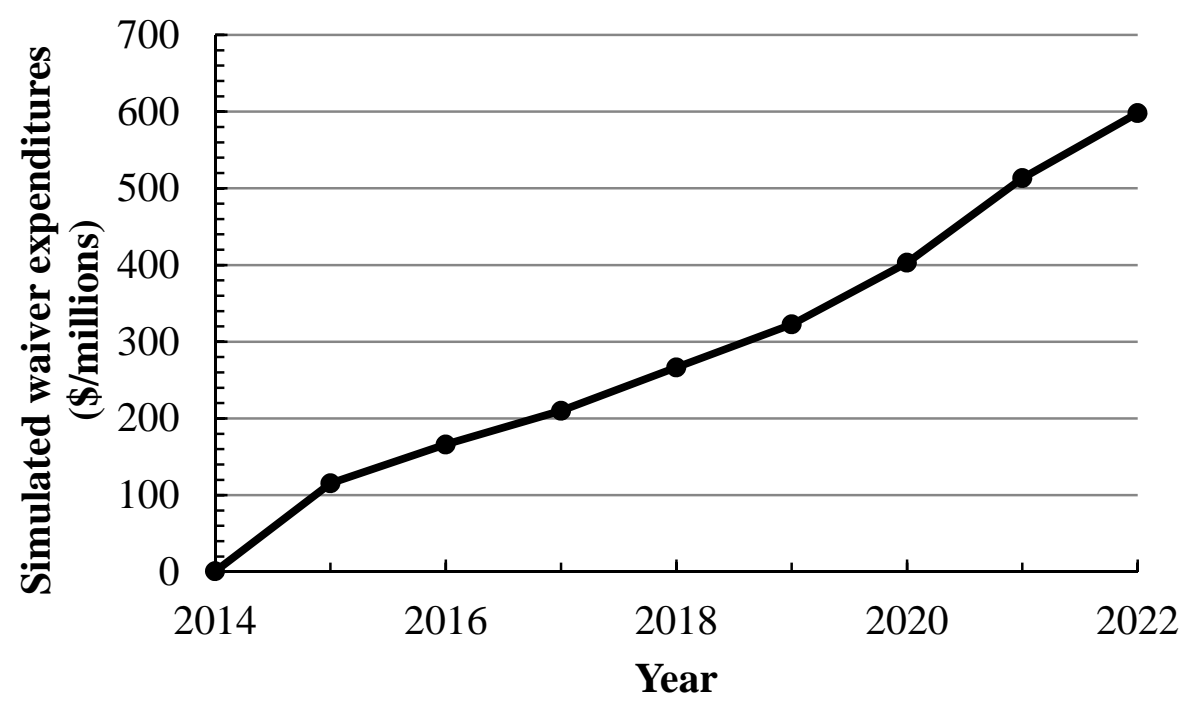

Fig. 4. Simulated effect of an increase in the mandated percentage of cellulosic ethanol $\left(Z^{c}\right)$ in blended fuel on total waiver cost.

Next, we simulate the effect of a gradual increase in the price of cellulosic biofuel waiver credits. Starting with the 2012 price of 78 cents per waiver credit, we examine the impact on production of cellulosic ethanol as the waiver price increases to $\$ 2.23$ in five cent increments. ${ }^{19}$ As shown in Fig. 5, the increase in cellulosic ethanol is more dramatic starting from about 660 thousand gallons at the current waiver price to just over 6.6 million gallons at the high end of the considered waiver prices. The increase in cellulosic ethanol rises at a decreasing rate.

Our model also allows us to examine how changes in the waiver price affect the growth of the refined cellulosic industry. As the waiver price increases, the blended fuel sector increases its

\footnotetext{
${ }^{19}$ Given the waiver price structure, $g$, a $\$ 2.23$ waiver price implies a maximum retail gasoline price of $\$ 5.23 /$ gal from the relationship $g=\max \left[0.25, p_{g}-3\right]$.
} 
demand for cellulosic ethanol. This increase leads to an increase in the demand for capital in the cellulosic feedstock refining sector consequently increasing the capital to labor ratio in the cellulosic refining sector as shown in Fig. 6. Such a change signifies an increase in capital investment and growth in the sector. There is a 4-fold increase in the capital/labor ratio when the waiver price reaches $\$ 2.23$ which implies an arc elasticity of the capital/labor ratio to waiver price of 2.35 .

To accommodate the increased demand for capital from the cellulosic sector, capital flows out of the agricultural and forestry sectors devoted to composite commodity production and reduces the amount of composite commodity available to the consumption sector. When the waiver price reaches $\$ 2.23 /$ credit, composite commodity consumption decreases by 3.56\% but blended fuel consumption by the consumer barely changes. Because the blended fuel producer simply substitutes away from crude oil towards cellulosic ethanol as the waiver price increases, the change in total blended fuel consumption is less than $0.01 \%$ when the waiver price increases from 78 cents to $\$ 2.23 /$ credit.

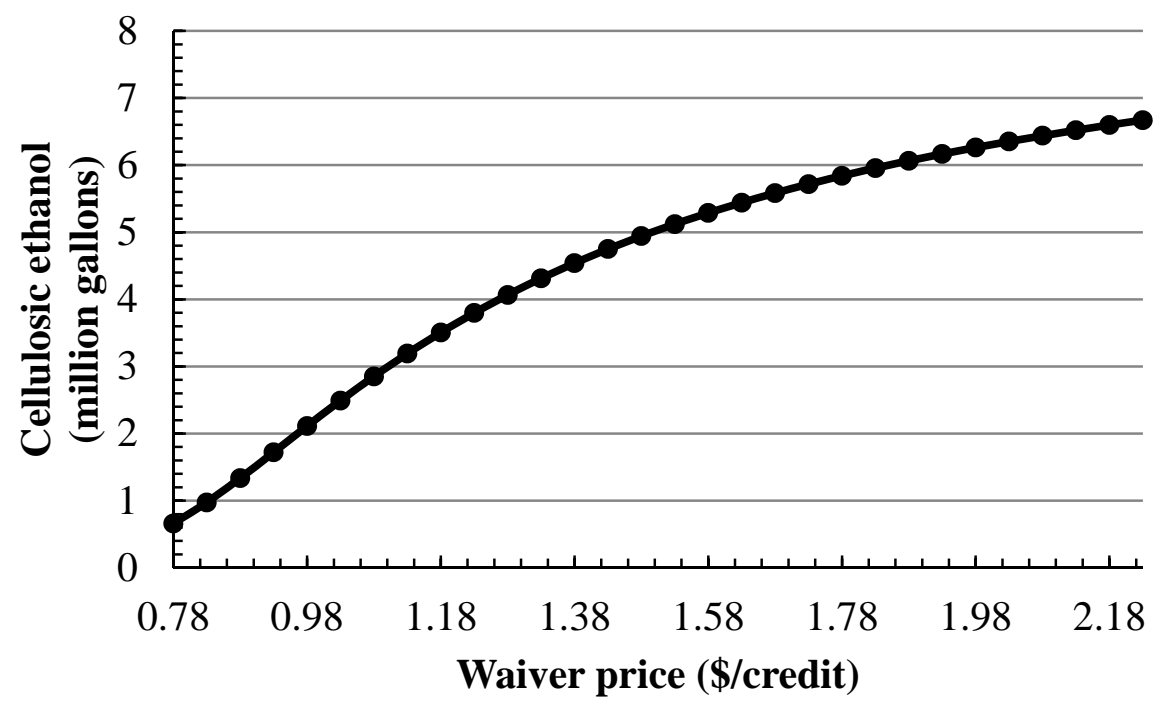

Fig. 5. Simulated effect of an increase in the waiver price $(g)$ on cellulosic ethanol $\left(Y^{c}\right)$. 


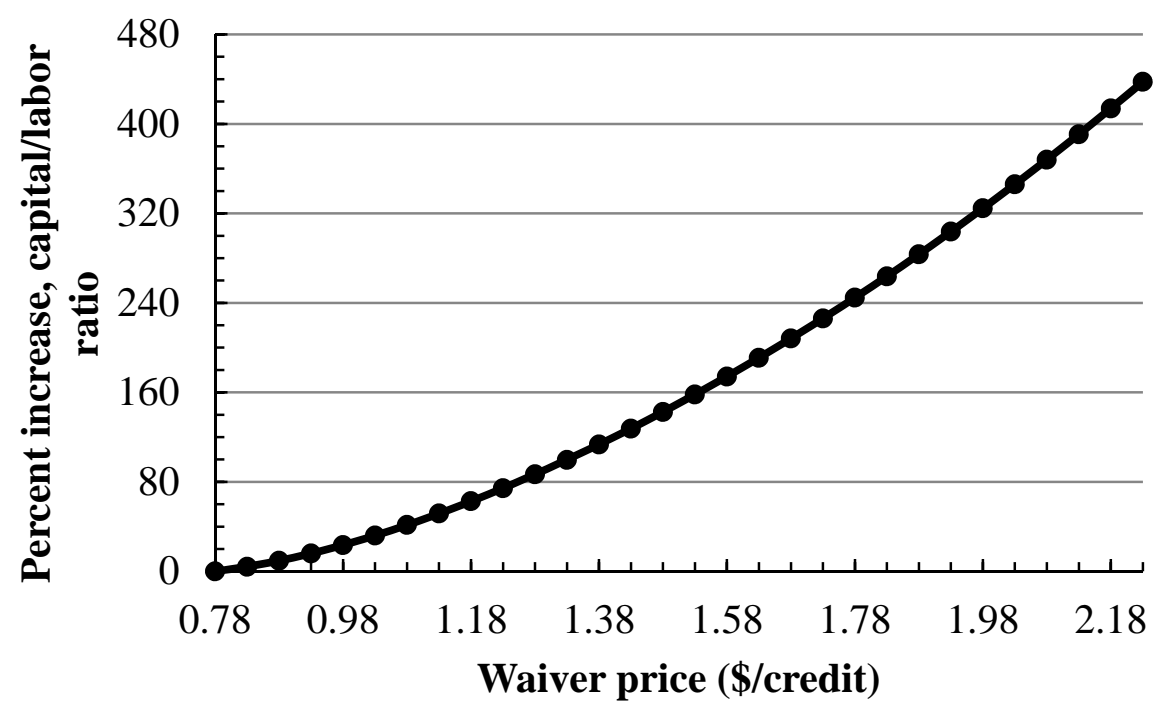

Fig. 6. Simulated effect on an increase in waiver price $(g)$ on the capital/labor ratio in the cellulosic refining sector.

\subsection{Change in market power}

Growth in the refined cellulosic fuel sector could be accompanied by changes in the market power of firms within that sector and influence the equilibrium quantity of cellulosic ethanol.

Based on our partial equilibrium results, more firms translate to an increase in supply of cellulosic ethanol. We simulate the general equilibrium effect of changes in oligopolistic market power among refined cellulosic firms by increasing the number of firms in the refined cellulosic sector. As demonstrated in Fig. 7, increasing the number of firms in the cellulosic refining sector increases the equilibrium level of cellulosic ethanol at a decreasing rate which verifies the partial equilibrium prediction. 


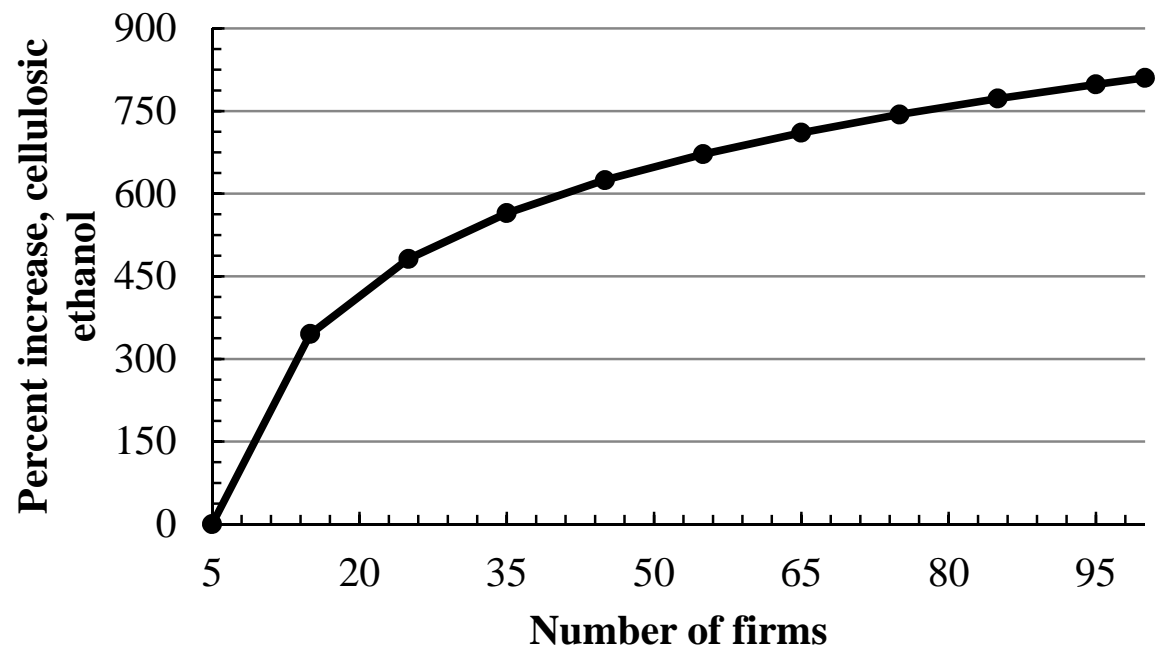

Fig. 7. Simulated effect of an increase in the number of firms $(n)$ on cellulosic ethanol $\left(Y^{c}\right)$.

We are also interested in the impact of a change in market structure on the marginal effect of the RFS on the equilibrium level of cellulosic ethanol. An increase in the number of firms in the cellulosic refining sector has no discernible effect on the marginal contribution of the RFS on cellulosic ethanol. Instead, there is a parallel shift of the curve relating RFS and cellulosic ethanol as illustrated for the 2012 waiver price in Fig. 8 for increases in the number of firms in the cellulosic refining sector.

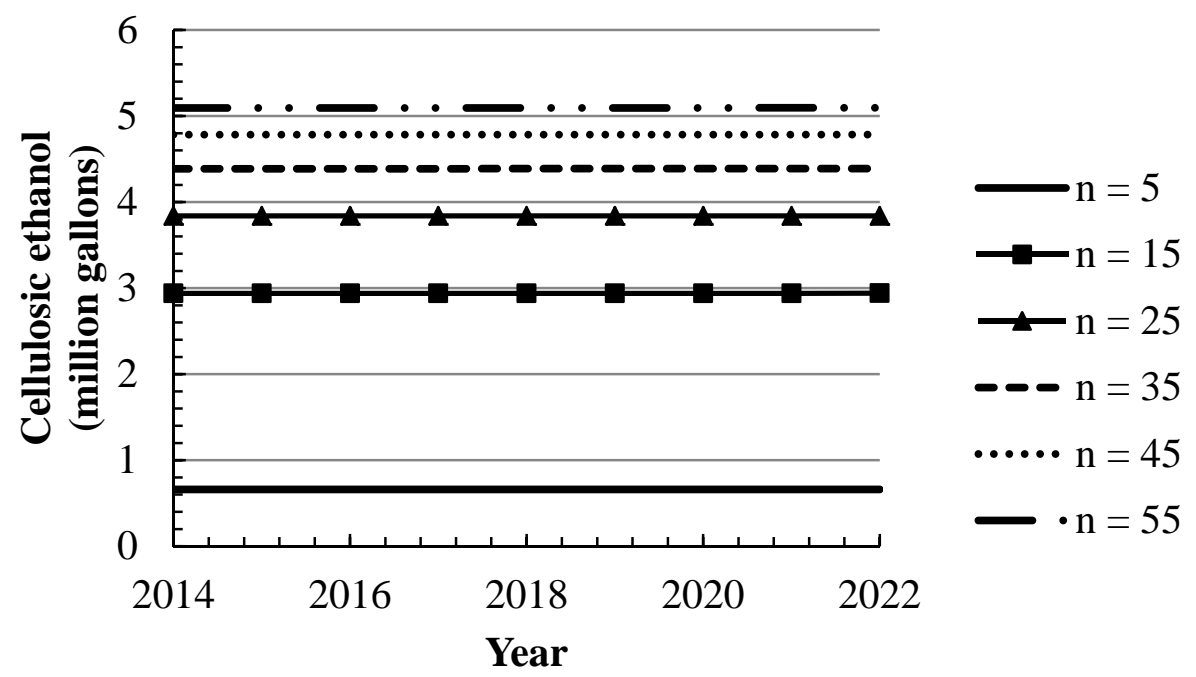

Fig. 8. Simulated effect of the increasing RFS $\left(Z^{c}\right)$ on cellulosic ethanol $\left(Y^{c}\right)$ for varying $n$. 
However, the effect of changes in market structure on the relationship between waiver price and cellulosic ethanol is more dramatic as summarized in Fig. 9. We find that as the number of firms rise, there is an increase in cellulosic ethanol at a decreasing rate at a given waiver price. As the waiver price rises, its marginal contribution to increasing cellulosic ethanol decreases as more firms are added.

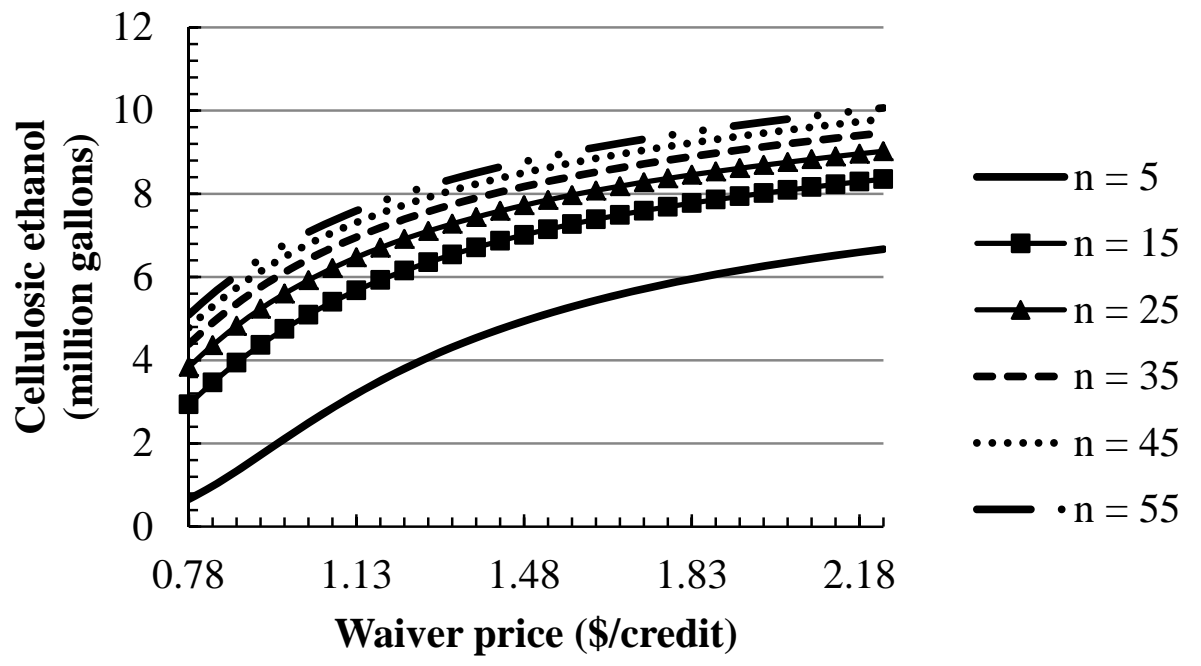

Fig. 9. Simulated effect of an increase in waiver price $(g)$ on cellulosic ethanol $\left(Y^{c}\right)$ for varying $n$.

The equilibrium price of cellulosic ethanol rises as waiver prices increase and is higher with fewer firms as shown in Fig. 10. It is interesting to point out that it is not monotonically increasing for all market structures. For the case of an oligopoly, equilibrium price decreases before eventually rising. This U-shaped relationship can be explained by the relative shifts in supply and demand as a response to a change in the waiver price. An increase in the waiver price increases demand by fuel blenders but it also shifts the supply curve to the right as illustrated by the increase in capital and other inputs in the refined cellulosic sector. If the supply increase is greater (less) than the demand increase, equilibrium price declines (rises). In the case of perfect 
competition, the demand increase is larger than the supply increase leading to a simultaneous increase in equilibrium quantity and price of cellulosic ethanol. For an oligopoly, the increase in supply is larger than the increase in demand at low levels of waiver price but the relationship is reversed at higher waiver price levels. The magnitude of the supply shift is determined by the elasticity of cellulosic ethanol supply with respect to a change in the waiver price.

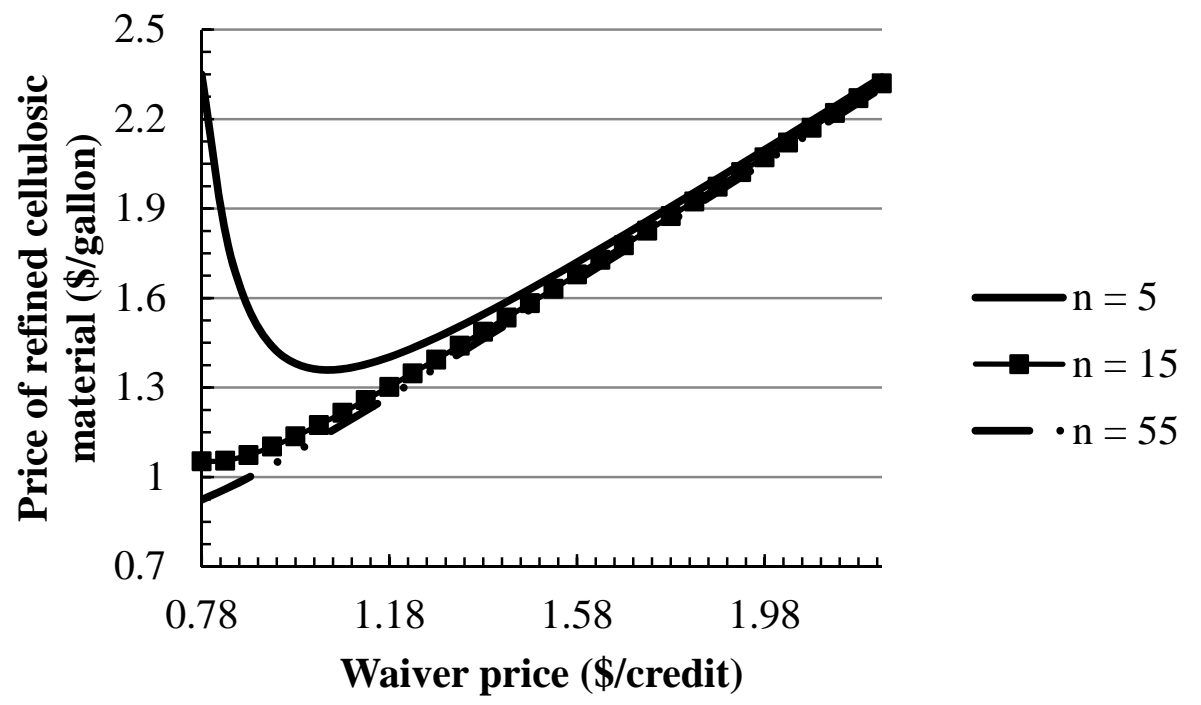

Fig. 10. Simulated effect of an increase in waiver price $(g)$ on the price of cellulosic ethanol $\left(p^{c}\right)$ for varying $n$

As illustrated in Fig. 11, when the market structure is an oligopoly, the elasticity is large at low waiver prices at 7.5 as opposed to the case where there are more firms. The reason why the elasticity is higher under the case of fewer firms is because of an initially low aggregate output of cellulosic ethanol when an oligopoly exists compared to perfect competition. Thus, a small change in the waiver price will elicit a relatively large change in equilibrium quantity of cellulosic ethanol which leads to a higher elasticity. The elasticity initially increases as waiver price rises which leads to a larger shift in the supply curve relative to the demand curve and a decline in equilibrium price. After the waiver price exceeds $\$ 1$, the elasticity declines which leads to a smaller increase in supply relative to demand and an increase in equilibrium price. 


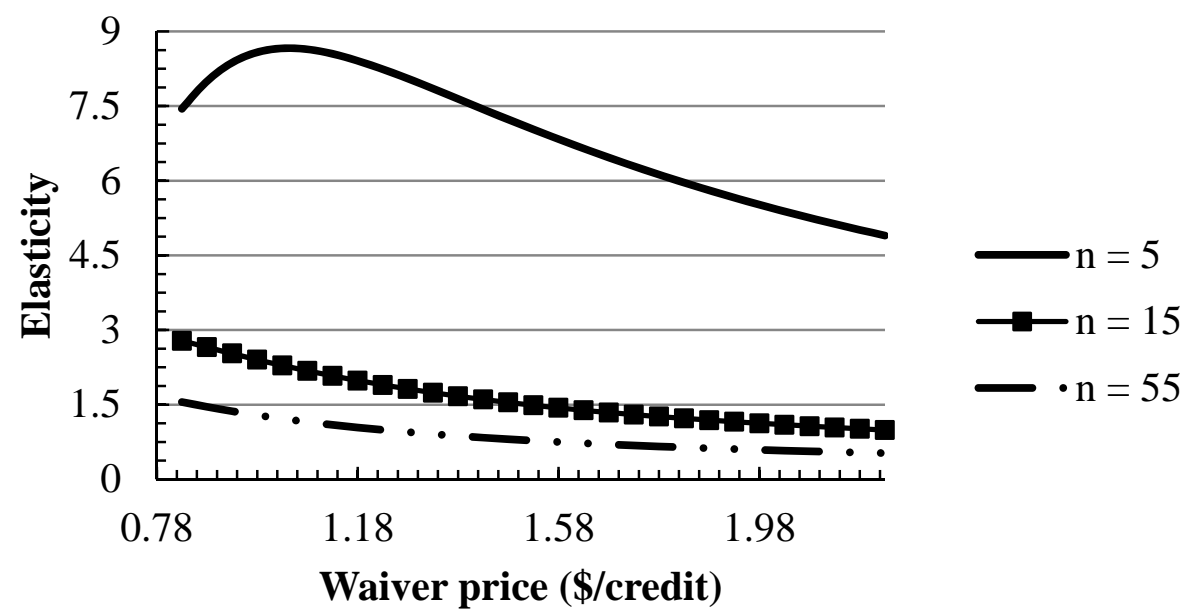

Fig. 11. Simulated elasticity of cellulosic ethanol $\left(Y^{c}\right)$ with respect to a change in waiver price $(g)$ for varying $n$.

In the case when there are a large number of firms, the elasticity of cellulosic ethanol given a change in the waiver price ranges from 1.5 to 2 at the prevailing waiver price. The elasticity declines as the waiver price increases to approximately 0.5 . This elasticity is fundamentally an estimate of the own-price supply elasticity, which puts it in the upper range of short-run supply elasticities for agriculture and forestry, the sources of cellulosic feedstock. For example, recent estimates of the domestic corn and canola supply elasticities are 0.23 and 0.07 , respectively (Gardner, 2007; Zheng and Shumway, 2012). Earlier estimates of U.S. feed grain, oilseed, and feed elasticities range from 0.10 to 0.42 (Shumway et al., 1988; Williams and Shumway, 2000). North Carolina pulpwood and Southern saw timber supply elasticity estimates range from 0.08 to 1.27 (Pattanayak et al., 2002; Prestemon and Wear, 2000). Thus, while our estimates are at the high end of these related supply elasticities, our simulations illustrate a credible response in cellulosic ethanol supply given a change in the waiver price in a market structure close to perfect competition. 


\subsection{Simulation robustness checks}

Our simulation assumed that the blended fuel sector was perfectly competitive while the cellulosic ethanol sector ranged from oligopoly to perfect competition. Only five refineries are responsible for supplying transportation fuel to the Pacific Northwest (Washington State and Oregon in particular) (EIA, 2013d). Thus, the firms likely have oligopolistic power in the final blended fuel output market. In terms of the crude oil input, the firms likely have oligopsonistic power as well. For instance, approximately fifty percent of the crude oil produced in Alaska is shipped to Washington, and approximately fifty percent of the crude oil supplied by the Trans Mountain Pipeline in Canada is pumped to refineries in Northwest Washington (EIA, 2013d; Trans Mountain, 2013). Due to the prevailing transportation infrastructure, it is costly for the crude oil producers in Alaska and the producers supplying the Trans Mountain Pipeline to ship to alternate refiners. Thus, the refiners in Washington could be oligopsonies in the purchase of crude oil as an input in producing fuel.

We simulate the effect of the RFS and the waiver price under the assumption of a perfectly competitive refined cellulosic sector and an oligopoly/oligopsony blended fuel sector. Similar to our previous result, any increase in the RFS had little to no impact on the equilibrium level of cellulosic ethanol, as shown in Fig. 12, because of a large increase in the purchase of relatively cheaper waiver credits. In contrast, an increase in the waiver price resulted in a rise in cellulosic ethanol as shown in Fig. 13 with an approximate elasticity of 0.13 which puts it squarely in the range of short-run supply elasticities for agricultural and forestry feedstock sources. Thus, even when we allow for imperfect competition in the blended fuel sector, the qualitative results continue to hold. 


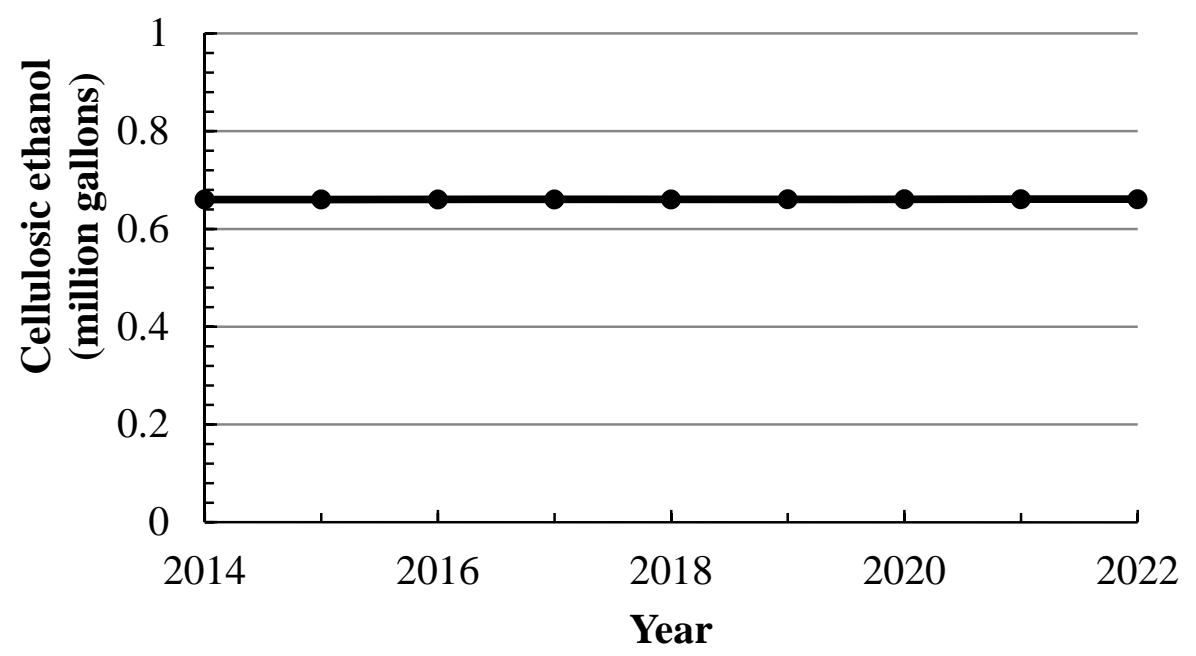

Fig. 12. Simulated effect of the increasing RFS $\left(Z^{c}\right)$ on cellulosic ethanol $\left(Y^{c}\right)$ under an oligopoly/oligopsony blended fuel market structure.

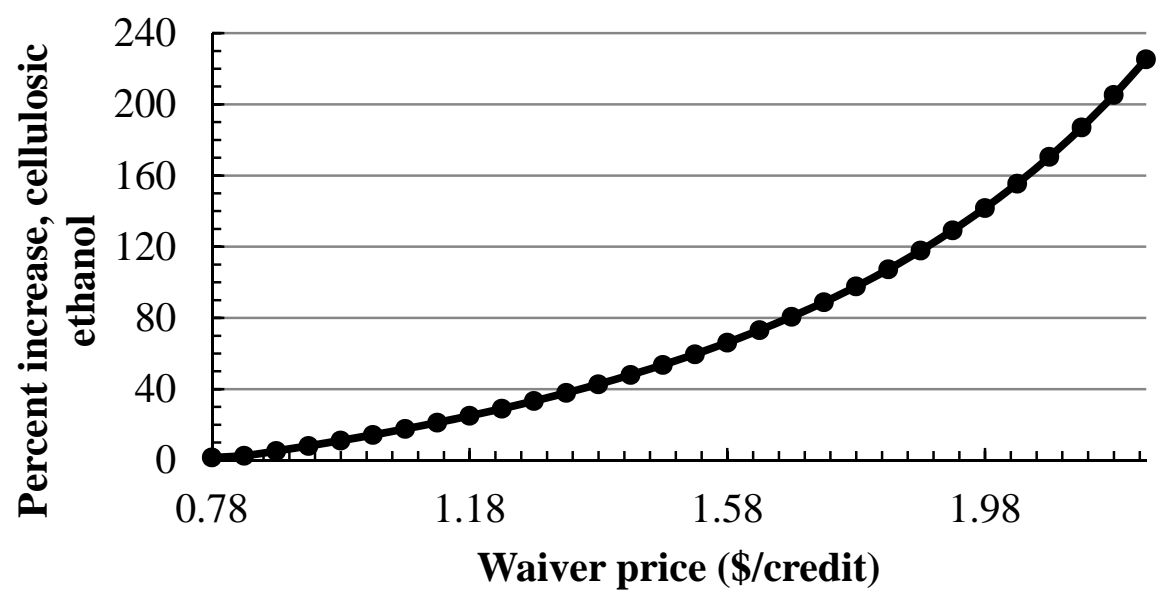

Fig. 13. Simulated effect of an increase in the waiver price $(g)$ on cellulosic ethanol $\left(Y^{c}\right)$ under an oligopoly/oligopsony blended fuel market structure.

\section{Conclusion}

This article examines the effect of the Renewable Fuel Standards and market power on the cellulosic biofuels sector. We develop a sectoral model that includes two feedstock sectors, a cellulosic refining sector, a blended fuel sector, a composite good producing sector and a consumption sector to show how changes in the regulations governing cellulosic fuel affect the equilibrium quantity of cellulosic ethanol. We find that an increase in the standards do not significantly affect the equilibrium quantity for cellulosic ethanol as long as firms are given the 
opportunity to purchase waivers. This finding stands in sharp contrast to the effects of a standard on inputs alone as modeled in Helfand (1991). Instead, firms purchase more waivers because it is relatively less expensive to do so. In contrast, moderately higher waiver prices increase the equilibrium quantity for cellulosic ethanol. These qualitative results apply to other states that face the RFS. Further, for other countries that want to support growth of a cellulosic ethanol market, our analysis suggests that providing a waiver is only helpful as long as the price of the waiver is not lower than the shadow price of cellulosic ethanol.

The results have important implications in terms of technological adoption. Because of cheap waivers, the RFS standard has failed to significantly increase demand for cellulosic ethanol. Consequently, there is very little incentive for firms to develop and adopt new technology that would facilitate development of the cellulosic ethanol sector.

The refined cellulosic sector may initially be an oligopoly with few commercial producers, but this could change over time. The equilibrium quantity of cellulosic ethanol rises as more firms enter, but the marginal effect of an increase in the waiver price on the quantity of cellulosic ethanol is smaller under perfect competition than oligopoly.

Our sectoral model highlights results that a partial equilibrium analysis is not able to pick up. We show the need to revise the federal biofuel mandate if more cellulosic ethanol is to be included in blended fuel. While other papers relying on partial equilibrium analysis have suggested raising the standards, our general equilibrium analysis finds that doing so has minimal effect. Rather, we find that substantially increasing the price of the waiver could have a significant impact on cellulosic ethanol because it not only increases demand for cellulosic ethanol but also increases the size of the industry through capital investments as shown by a rise in the capital-labor ratio of the sector. 
Our results have important policy implications. The high cost of cellulosic ethanol production is often cited as the cause of the lack of cellulosic ethanol production, which is in turn used to justify low waiver prices as a release valve. However, we show that the currently low waiver price is a significant reason for cellulosic ethanol market stagnation in the context of the current biofuel policy. This policy implication has received little attention in the popular or academic literature.

Our results also point to some interesting avenues for future research. We find an increase in capital investment in refined cellulosic sector as the waiver price is raised or waivers are eliminated. However, to fully measure growth in the industry, a dynamic extension showing capital investment accumulation over time is needed. Such a change can potentially forecast the evolution of the market structure over time.

\section{Acknowledgments}

This research was supported by Agriculture and Food Research Initiative Competitive Grant no. 2012-67009-19707 from the USDA National Institute of Food and Agriculture. We thank three reviewers who helped focus and clarify important points of the manuscript. 


\section{References}

Anderson, J.D., Coble, K.H., 2010. Impact of Renewable Fuels Standard ethanol mandates on the corn market. Agribusiness 26 (1), 49-63.

Backus, D., Crucini, M., 2000. Oil prices and the terms of trade. Journal of International Economics 50, 185-213.

Banks J., Blundell, R., Lewbel, A., 1997. Quadratic Engel curves and consumer demand. The Review of Economics and Statistics 79 (4), 527-539.

BLS (U.S. Bureau of Labor Statistics), 2013. May 2012 State Occupational Employment and Wage Estimates: Washington State. Available at: http://www.bls.gov/oes/current/oes_wa.htm\#45-0000 (accessed September 2013).

Bovenberg, A.L., Goulder, L.H., 1996. Optimal environmental taxation in the presence of other taxes: general-equilibrium analyses. The American Economic Review 86, 985-1000.

Chen, X. and Khanna, M. Food vs. Fuel: The Effect of Biofuel Policies. American Journal of Agricultural Economics 98(1): 1-7. doi: 10.1093/ajae/aas039.

Daniels, J.M., 2010. Assessing the lumber manufacturing sector in western Washington. Forest Policy and Economics 12, 129-135.

EIA (U.S. Energy Information Administration), 2013a. Cellulosic biofuels begin to flow but in lower volumes than foreseen by statutory targets. Available at: http://www.eia.gov/todayinenergy/detail.cfm?id=10131 (accessed April 2014).

— _ 2013b. Spot prices for crude oil and petroleum products. Available at: http://www.eia.gov/dnav/pet/pet_pri_spt_s1_d.htm (accessed September 2013). 
— _ 2013c. West Coast less California gasoline and diesel retail prices. Available at: http://www.eia.gov/dnav/pet/pet_pri_gnd_dcus_r5xca_a.htm (accessed September 2013).

— . 2013d. Washington State profile and energy estimates: profile analysis. Available at: http://www.eia.gov/state/analysis.cfm?sid=WA (accessed December 2013).

— 2016. Petroleum and other liquids: Supply and disposition. Available at: http://www.eia.gov/dnav/pet/pet_sum_snd_d_nus_mbbl_m_cur.htm (accessed March 2016).

EPA (U.S. Environmental Protection Agency), 2007. Regulation of fuels and fuel additives: Renewable Fuel Standard program. Federal Register 72 (83), 23900-24014.

—_. 2010. Regulation of fuels and fuel additives: 2011 Renewable Fuel Standards. Federal Register 75 (236), 76790-76830.

—_. 2012. Regulation of fuels and fuel additives: 2012 Renewable Fuel Standards. Federal Register 77 (5), 1320-1358.

—_. 2013a. Regulation of fuels and fuel additives: 2013 Renewable Fuel Standards. Federal Register 78 (158), 49794-49830.

—. 2013b. RFS2 EMTS informational data, 2012 RFS2 data. Available at: http://www.epa.gov/otaq/fuels/rfsdata/2012emts.htm (accessed October 2013).

—_. 2015. Renewable Fuel Standard program: Standards for 2014, 2015, and 2016 and biomass-based diesel volume for 2017. Federal Register 80 (239), 77419-77518. ERS (USDA Economic Research Service), 2014. National tables, 1948-2011, tractor rental rate. Available at: http://www.ers.usda.gov/data-products/agricultural-productivity-in-theus.aspx (accessed February 2014). 
Fullerton, D., Heutel, G., 2007. The general equilibrium incidence of environmental taxes. Journal of Public Economics 91, 571-591.

Gale, C.B., Keegan III, C.E., Berg, E., Daniels, J., Christensen, G.A., Sorenson, C.B., Morgan, T.A., Polzin, P., 2012. Oregon’s forest products industry and timber harvest, 2008: industry trends and impacts of the great recession through 2010. USDA General Technical Report PNW-GTR-868.

Gallagher, P.W., Shapouri, H., Price, J., Schamel, G., Brubaker, H., 2003. Some long-run effects of growing markets and Renewable Fuel Standards on additives markets and the US ethanol industry. Journal of Policy Modeling 25, 585-608.

Gardner, B.L., 2007. Fuel ethanol subsidies and farm price support. Journal of Agricultural \& Food Industrial Organization 5 (2), 1-20.

Goulder, L.H., Hafstead, M.A.C., Williams III, R.C., 2014. General equilibrium impacts of a federal clean energy standard. Resources for the Future Working Paper RFF DP 14-02.

GBC (Governors’ Biofuel Coalition), 2011. Cellulosic ethanol won’t reach first-generation price until 2020 — study. Available at: http://www.governorsbiofuelscoalition.org/?p=679 (accessed September 2013).

GPO (Government Printing Office), 2011. Code of Federal Regulations, Title 40, Part 80.1456. Available at: http://www.gpo.gov/fdsys/browse/collectionCfr.action?collectionCode=CFR (accessed October 2014).

Helfand, G.E., 1991. Standards versus standards: the effects of different pollution restrictions. The American Economic Review 81, 622-634. 
McCullough, M., Holland, D. Painter, K., Stodick, L. Yoder, J. 2011. Economic and environmental impacts of Washington state biofuel policy alternatives. Journal of Agricultural and Resource Economics 36, 615-629.

McPhail, L.L., Babcock, B.A., 2008a. Ethanol, mandates, and drought: insights from a stochastic equilibrium model of the U.S. corn market. Working Paper 08-WP464, Center for Agricultural and Rural Development, Iowa State University.

McPhail, L.L., Babcock, B.A., 2008b. Short-run price and welfare impacts of federal ethanol policies. Working Paper 08-WP 468, Center for Agricultural and Rural Development, Iowa State University.

McPhail, L., Westcott, P., Lutman, H., 2011. The Renewable Identification Number system and US biofuel mandate. USDA BIO-03 November 2011. A report from the Economic Research Service.

Miao, R., Hennessy, D.A., Babcock, B.A., 2012. Investment in cellulosic biofuel refineries: do waivable biofuel mandates matter? American Journal of Agricultural Economics 94 (3), $750-762$.

NASS (USDA National Agricultural Statistics Service), 2013a. Quick Stats: rent, cash, croplandexpense. Available at: http://quickstats.nass.usda.gov/results/95303089-CE93-3EED9B56-68C096A8B8CB (accessed September 2013).

—. 2013b. Quick Stats: tractors-inventory. Available at: http://quickstats.nass.usda.gov/results/3EE349F8-6DF1-30C4-BCA0-C67A886F25A8 (accessed September 2013). 
—. 2013c. Quick Stats: area cropland, harvested. Available at: http://quickstats.nass.usda.gov/results/93F20082-8A27-3E48-9524-37A2749EE556 (accessed September 2013).

—. 2013d. Crop Values: 2012 Summary. Available at: http://usda.mannlib.cornell.edu/usda/nass/CropValuSu//2010s/2012/CropValuSu-02-162012.pdf (accessed September 2013).

Pattanayak, S.K., Murray, B.C., Abt, R.C., 2002. How joint is joint forest production? An econometric analysis of timber supply conditional on endogenous amenity values. Forest Science 48 (3), 479-91.

Prestemon, J.P., Wear, D.N., 2000. Linking harvest choices to timber supply. Forest Science 46 (3), 377-389.

Schill, S.R., 2012. Blue Sugars claims first cellulosic RIN, extends Petrobras deal. Available at: http://www.ethanolproducer.com/articles/8919/blue-sugars-claims-first-cellulosic-rinextends-petrobras-deal (accessed October 2014).

Schnepf, R., Yacobucci, B.D., 2013. Renewable Fuel Standard (RFS): overview and issues in agricultural policy. CRS Report R40155. Library of Congress, Congressional Research Service, Washington, D.C.

Shumway, C.R., Saez, R.R., Gottret, P.E., 1988. Multiproduct supply and input demand in U.S. agriculture. American Journal of Agricultural Economics 70 (2), 330-337.

Sims, R.E.H., Mabee, W., Saddler, J.N., Taylor, M., 2010. An overview of second generation biofuel technologies. Bioresource Technology 101(6), 1570-1580. 
Smith, D., 2012. Washington mill survey 2010: series report \#21. Washington State Department of Natural Resources. Available at: http://www.dnr.wa.gov/Publications/obe_econ_rprt_millsurv_2010.pdf (accessed September 2013).

Trans Mountain, 2013. Home Page. Available at: http://www.transmountain.com/pipeline (accessed December 2013).

University of Kentucky, 2013. Switchgrass for bioenergy. University of Kentucky College of Agriculture Cooperative Extension Service. Available at: https://www.uky.edu/Ag/CDBREC/introsheets/switchgrass.pdf (accessed September 2013).

Westcott, P., McPhail, L.L., 2013. High RIN prices signal constraints to U.S. ethanol expansion. Feed Outlook: Special Article FDS-13d-SA. USDA ERS, Washington, D.C.

Williams, S.P., Shumway, C.R., 2000. Trade liberalization and agricultural chemical use: United States and Mexico. American Journal of Agricultural Economics 82, 183-199.

Woodward, W.T., 2008. The potential for alfalfa, switchgrass and Miscanthus as biofuel crops in Washington. In Proceedings of the Washington State Hay Growers Association Annual Conference and Trade Show, Three Rivers Convention Center, Kennewick, WA, pp. 1-7. WRC (Washington Research Council). 2012. The Economic Contribution of Washington State’s Petroleum Refining Industry in 2011. Economic Profile. Available at: https://researchcouncil.files.wordpress.com/2013/08/2012refineryreportfinal040913.pdf (accessed March 2015). 
Yacobucci, B.D., 2013. Analysis of Renewable Identification Numbers (RINs) in the Renewable Fuel Standard (RFS). CRS Report R42824. Library of Congress, Congressional Research Service, Washington, D.C.

Yi, F., Mérel, P., Lee, J., Hossein Farzin, Y., Six, J., 2014. Switchgrass in California: where, and at what price? GCB Bioenergy 6, 672-686.

Yoder, J., Shumway, C.R., Wandschneider, P., Young, D., Chouinard, H., Espinola-Arredondo, A., Galinato, S., Frear, C., Holland, D., Jessup, E., LaFrance, J., Lyons, K., McCullough, M., Painter, K., Stodick, L., 2010. Biofuel economics and policy for Washington State. Washington State Univ. Agr. Res. Center Res. Bul. XB1047E. Available at: http://cru.cahe.wsu.edu/CEPublications/XB1047E/XB1047E.pdf (accessed October 2014).

Zheng, Q., Shumway, C.R., 2012. Washington biofuel feedstock crop supply under output price and quantity uncertainty. Energy Policy 48, 515-525. 